\title{
Familial multinodular goiter syndrome with papillary thyroid carcinomas: mutational analysis of the associated genes in 5 cases from 1 Chinese family
}

Shunyao Liao ${ }^{1^{*}}$, Wenzhong Song ${ }^{2^{*}}$, Yunqiang Liu ${ }^{3}$, Shaoping Deng ${ }^{1,4}$, Yaming Liang ${ }^{1}$, Zhenlin Tang ${ }^{2}$, Jiyuan Huang ${ }^{2}$, Dandan Dong ${ }^{5}$ and Gang $\mathrm{Xu}^{5}$

\begin{abstract}
Background: Familial papillary thyroid cancer (fPTC) is recognized as a distinct entity only recently and no fPTC predisposing genes have been identified. Several potential regions and susceptibility loci for sporadic PTC have been reported. We aimed to evaluate the role of the reported susceptibility loci and potential risk genomic region in a Chinese familial multinodular goiter (fMNG) with PTC family.

Methods: We sequenced the related risk genomic regions and analyzed the known PTC susceptibility loci in the Chinese family members who consented to join the study. These loci included (1) the point mutations of the BRAF and RET; (2) the possible susceptibility loci to sporadic PTC; and (3) the suggested potential fMNG syndrome with PTC risk region.

Results: The members showed no mutations in the common susceptible BRAF and RET genomic region, although contained several different heterozygous alleles in the RET introns. All the members were homozygous for PTC risk alleles of rs966423 (C) at chromosome 2q35, rs2910164 (C) at chromosome 5q24 and rs2439302 (G) at chromosome 8p12; while carried no risk allele of rs4733616 (T) at chromosome 8q24, rs965513 (A) or rs1867277 (A) at chromosome 9q22 which were associated with radiation-related PTC. The frequency of the risk allele of rs944289 (T) but not that of rs116909374 (T) at chromosome 14q13 was increased in the MNG or PTC family members.

Conclusions: Our work provided additional evidence to the genetic predisposition to a Chinese familial form of MNG with PTC. The family members carried quite a few risk alleles found in sporadic PTC; particularly, homozygous rs944289 (T) at chromosome 14q13 which was previously shown to be linked to a form of fMNG with PTC. Moreover, the genetic determinants of radiation-related PTC were not presented in this family.
\end{abstract}

Keywords: Familial papillary thyroid carcinomas, Multinodular goiter syndrome, Mutational analysis, Genetic association, Risk alleles

\footnotetext{
* Correspondence: shunyaol@yahoo.com; wz360@hotmail.com

${ }^{1}$ Diabetes \& Endocrinology Center, Sichuan Academy of Medical Science, Sichuan Provincial People's Hospital, Chengdu 610072, China

2Department of Thyroid Disease \& Nuclear Medicine, Sichuan Academy of Medical Science, Sichuan Provincial People's Hospital, Chengdu 610072,

China

Full list of author information is available at the end of the article
} 


\section{Background}

PTC is the most prevalent malignancy of the thyroid gland. There has been an increasing incidence of PTC worldwide for the past few decades. The etiology of PTC is related to environmental, hormonal and genetic factors. About 5-15\% of PTC patients show a familial occurrence, and fPTC is recognized as a distinct entity only in recent years $[1,2]$. Families with accumulation of PTCs show an inherited trait of the disease and patients with PPTC often have early age at disease onset and increased severity in successive generations, also, fPTC patients frequently present more aggressive tumors with increased incidence of multifocality, local invasion, lymph node metastases than the sporadic PTC $[2,3]$. Generally, fPTC is diagnosed when three or more family members have PTC and in the absence of other known associated syndromes $[1,2]$. PTC has a significant gender bias with much more women affected than men; it is especially suggestive for the familial predisposition when men or children were diagnosed with PTC $[1,4]$. While, because families share the same environment and a common genetic background, it is difficult to distinguish between environmental and genetic contributing factors, and also because the majority of fPTC pedigrees are small in size and may present with a variety of additional benign thyroid nodules, the genetic predisposition to PPTC is unknown and the molecular alterations at the origin of the pathology are only now beginning to emerge $[1,5,6]$.

Sporadic PTC is known to be associated with point mutation of the $B R A F$ genes and chromosomal rearrangements of RET/PTC. The BRAF encodes a serine/ threonine-protein kinase which plays a role in regulating the MAP kinase/ERKs signaling pathway and affects cell division, differentiation and secretion; point mutations in $B R A F$ are found in up to $45 \%$ PTC cases [7]. The $R E T$ protooncogene is one of the receptor tyrosine kinases, cell-surface molecules that transduce signals for cell growth and differentiation; rearrangements of the RET are found in about $35 \%$ of sporadic PTC [7]. Although somatic mutations of the genes like $B R A F$ and $R E T$ exclusively play a causative role in sporadic thyroid cancer development, germline mutations of single nucleotide polymorphisms (SNPs) in these genes were also reported to act as modifiers in the cancer process $[8,9]$, it needs to mention here that in a Chinese population, SNPs of BRAF were shown to be associated with PTC [10], and thus it is intriguing to verify these mutations in PPTC families.

Recent studies based on population stratification have made progresses to identify several single nucleotide polymorphisms (SNPs) associated with PTC risk. For examples, (1) It was discovered that rs966423 at 2q35, locating into the intron region of the disrupted in renal carcinoma 3 gene (DIRC3), was significantly associate with European nonmedullary thyroid cancer (NMTC) by the genome- wide studies [11]. DIRC3 predicted a non coding RNA transcript with unknown function, the first 2 exons of DIRC3 replaced exon 1 of HSPBAP1 and formed a DIRC3-HSPBAP1 fusion transcript, which are associated with chromatin remodeling and stress response; (2) It was reported that the heterozygosity G/C of SNP rs2910164 at 5q24 within the precursor of microRNA-146a predisposed to PTC by altering expression of miR146a target genes in the Toll-like receptor and cytokine signaling pathway $[12,13]$; (3) The genome-wide study also identified that chromosomal 8q24 was associated with the risk of various cancers, particularly, rs4733616 at $8 \mathrm{q} 24$ was founded to be possibly associated with PTC risk in 26 European families [14-16]; (4) The rs2439302, located in the intron of HRG-beta1c at 8p12,was reported to be associated with neuregulin 1 (NRG1) and confer risk of thyroid cancer [11]. HRG-beta1c is one of the NRG1 isoforms and interacts with tyrosine kinase to increase its phosphorylation on tyrosine residues, playing critical roles in the growth and development of multiple organ system; (5) It was repeatedly observed that the rs965513 at 9q22.33 were the strong association signal for NMTC in European people [16-19] and it was proposed that the rs965513 might linked to the nearest thyroid transcription factor of forkhead family (FOXE1) gene, which likely plays a crucial role in thyroid morphogenesis; furthermore, some research indicated that rs1867277 within the FOXE1 5' UTR is also a causal variant in thyroid cancer susceptibility [16,20]; (6) Finally, both rs944289 and rs116909374 on 14q13.3 were observed to be strongly associated with NMTC in European people $[11,16-19,21]$. Nonetheless, all these genetic associations found by the genome-wide association studies have not been investigated in a family based study.

In addition, a few potential regions for harboring an fPTC gene have been reported: chromosomal region 1q21 linked to fPTC with papillary renal neoplasia [22], 2q21 linked to familial NMTC type 1 syndrome [23], and the telomere abnormalities and chromosome fragility might display in PPTC family [24]; Specifically, familial NMTC and its relationship with familial MNG are recognized as distinct clinical entities, and the molecular pathophysiology of MNG and PTC is different, indeed MNG1 is located at 14q [25]; however, one study in a kindred with MNG and PTC suggested that 14q32 linked to a form of inherited MNG syndrome with a significant risk of progression to PTC [26].

In the present report we studied 2 PTCs and 3 MNGs obtained from members of one Chinese family. This family was ascertained through initial identification of the proband, a 35-year-old men (III2, Figure 1). The probands's mother, 5 maternal aunts and 1 younger first cousin were diagnosed with MNG or PTC by different hospitals in China. The mode of inheritance in the family appeared to 


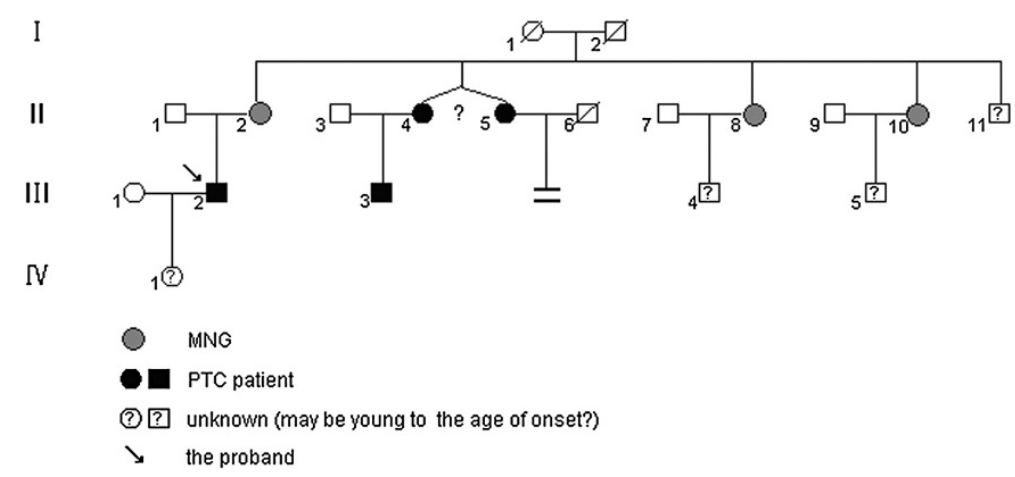

Figure 1 Pedigree of the Chinese fPTC. Circles and squares indicate female and male family members, respectively. The proband is indicated by an arrow.

be autosomal dominant. For the purpose to improve our understanding of the PTC predisposition, based on the recent progresses in genetic studies about PTC, we analyzed in this Chinese family (1) the point mutations of the $B R A F$ and RET; (2) the possible susceptibility loci to sporadic PTC; and (3) the suggested potential fMNG syndrome with PTC risk region.

\section{Methods}

\section{Patients}

The fMNG with PTC pedigree is reported in Figure 1. The clinical and pathological findings are summarized in Table 1.

The study protocol was approved by the Review Board of Clinical Research of the Sichuan Provincial hospital, and by the Research \& Ethics Committee of Sichuan Medical Research Institution. The blood samples were collected from the proband (III2), proband's parents (II1 \& 2) and maternal aunts (II5, 8, \& 10) with their written informed consent.

A 35-year-old man (Figure 1 III2) came to our observation: the man complained both his lymph nodes containing palpable lump for more than 10 days, initial ultrasound examinations revealed an $1.9 \times 1.4 \mathrm{~cm}$ solid mass with irregular \& indefinite border, sand calcification and blood flow in his right neck, and also 2 small nodule goiters in his left neck; The thyroid function tests showed the man was euthyroid; both the fine needle aspiration cytological and thyroidectomy specimen pathologic examinations disclosed that the architecture and nuclear features of the neoplasm in his both necks were typical for PTC (Figure 2A) and immunohistochemical staining confirmed the diagnosis (Figure 2B, C, D); After the total thyroidectomy and radioactive iodine treatment, the patient is now doing well. Interestingly, in terms of fMNG with PTC, the patient's mother is diagnosed with MNG in bilateral thyroid and underwent a total thyroidectomy in Chongqing, China (Figure 1 II2). Both of the patient's maternal twin aunts and a younger male cousin were diagnosed with MNG and PTC by different hospitals in Beijing and Chongqing, China, respectively; the other two maternal aunts were diagnosed with MNG by different hospitals in Chengdu and Dazhou, China, respectively (Figure 1 II8\&10).

\section{DNA extraction}

The whole blood was collected from the medial cubital vein into heparin anticoagulant tubes. The total DNA was purified using the spin protocol of QIAamp DNA Blood Mini Kit according to the manufacturer's directions (Qiagen, Hilden, Germany). The purified DNA was resuspended in TE buffer and stored at $4{ }^{\circ} \mathrm{C}$. Gel electrophoresis and spectrophotometric determination were used to DNA quantification and quality analysis. The OD260/OD280 ratio of DNA samples were between 1.82.0 and concentration was more than $100 \mathrm{ng} / \mathrm{ml}$.

Table 1 Clinical and pathological study of the collected samples

\begin{tabular}{llllll}
\hline Members & Sex & Age at diagnosis & Histology & sizes for PTCs and MNGs & Surgical treatment \\
\hline$\| 1$ & male & 64 & normal & & \\
$\| 2$ & female & 62 & bilateral MNG & MNG $(1.2 \mathrm{~cm})$, suspicious lesion & completion thyroidectomy \\
$\| 1 \mid 2$ & male & 35 & bilateral MNG with PTC & PTC in MNG, PTC $(1.6 \mathrm{~cm})$ & completion thyroidectomy \\
$\| 5$ & female & 56 & bilateral MNG with PTC & PTC in MNG, PTC $(1.5 \mathrm{~cm})$ & completion thyroidectomy \\
$\| 8$ & female & 45 & bilateral MNG & MNG $(0.3 \mathrm{~cm})$ & \\
$\| 10$ & female & 41 & MNG in right thyroid & MNG $(0.6 \mathrm{~cm})$ & \\
\hline
\end{tabular}



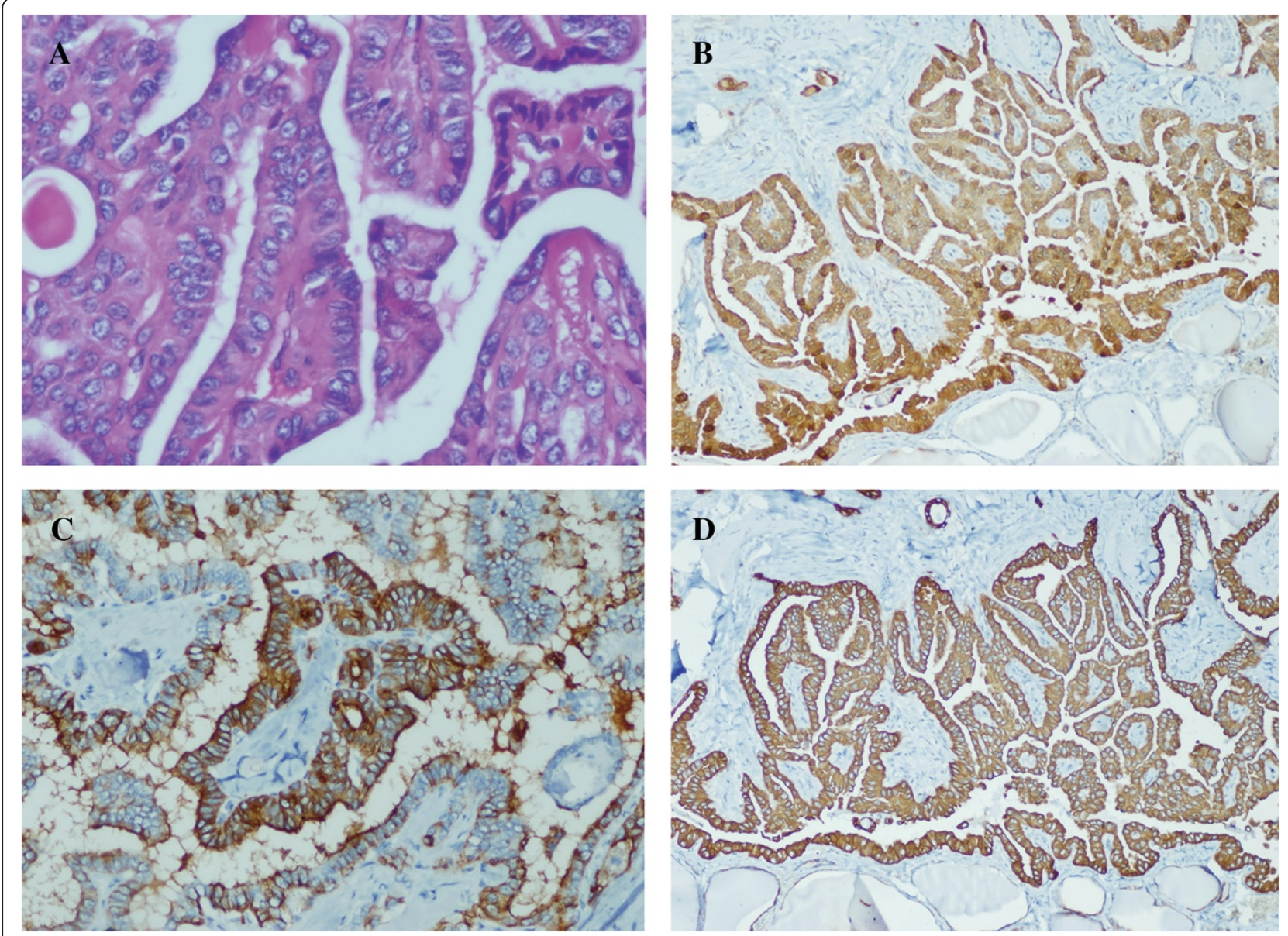

Figure 2 The histological features of the proband's papillary carcinoma. A: The cytological feature: crowded oval nuclei, nuclear grooves, clearing, elongation and overlapping $(\mathrm{HE} \times 400)$. B: Galectin-3 showed predominantly cytoplasmic staining with occasional nuclear staining (×200). C: HBME1 showed positive diffuse membrane (×200). D: Cytokeratin 19 showed strong, predominantly cytoplasmic staining ( $\times 200)$.

\section{Genetic mutational analysis}

The potential regions and susceptibility loci investigated in the study were listed in Table 2 . Sequencing was performed on PCR-amplified products using primers (Table 2) according to the published sequences or self-designed with Primer Premier 6.1 (PREMIER Biosoft, Palo Alto CA). The PCR amplifications were performed using ABI GeneAmp PCR System 9700 (Applied Biosystems, Foster City, CA). The PCR reaction system included 2U Pfu DNA polymerase (Thermo Fisher Scientific Inc, USA), $50 \mathrm{pmol}$ of each sense and antisense primers, $1 \times$ reaction buffer $(20 \mathrm{mM}$ Tris- $\mathrm{HCl}$ pH8.8, $10 \mathrm{mM} \mathrm{KCl}, 10 \mathrm{mM}$ $(\mathrm{NH} 4)_{2} \mathrm{SO}_{4}, 1 \%$ (v/v) Triton X-100), $250 \mu \mathrm{M}$ dNTP, $2.0 \mathrm{mM} \mathrm{MgCl}$ and $200 \mathrm{ng}$ genomic DNA in a total volume of $50 \mu \mathrm{l}$. The PCR cycling parameters were followed the recommendations for $P f u$ DNA polymerase according to the manufacturer. Precautions were taken to prevent PCR contamination, and indeed, in each experiment DNA template negative samples were run in parallel. The PCR products were resolved by electrophoresis in a $2 \%$ agarose gel stained with ethidium bromide and purifed using the QIAquick PCR purification kit (Qiagen). Purified PCR products were sequenced directly in both orientations using standard procedures with an ABI PRISM 3100 Genetic Analyzer (ABI, CA). The sequences were confirmed with two independent PCRs from two independent DNA samples.

\section{Results}

\section{The identification for the fMNG with PTC}

The histological features of the proband' papillary carcinoma were shown in Figure 2. The members of the Chinese family were diagnosed with MNG and PTC by different hospitals in China; the affected individuals showed typical MNG or MNG with PTC, bilateral and multicentric nodes. In this Chinese family, there were 2 first-degree blood relatives were diagnosed with bilateral MNG and PTC, 5 second-degree blood relatives including a pair of twin sisters were diagnosed with MNG or PTC; Also among these family members, 2 men (III2 
Table 2 Sequences of the primers

\begin{tabular}{|c|}
\hline ni \\
\hline BRAF at Chr7q34: $140,433,812-140,624,564(190,752 \mathrm{bp}$ \\
\hline $\begin{array}{l}\text { exon15: 176,372-176,490 (119 bp) K601E: 176,431(A- } \\
\text { G) rs121913364: 140,453,134 V600E: 176,429 (T } \rightarrow \text { A) } \\
\text { rs113488022: 140,453,136 }\end{array}$ \\
\hline RET at Chr10q11.2: $43,572,517-43,625,799$ \\
\hline $\begin{array}{l}\text { exon5: } 34,308-34,503(196 \text { bp) R313Q: } 34,378(G \rightarrow A) \\
\text { rs77702891: } 43,601,894 \text { R330Q: } 34,429(\mathrm{G} \rightarrow \mathrm{A}) \\
\text { rs80236571: } 43,601,945\end{array}$ \\
\hline $\begin{array}{l}\text { exon8: } 40,031-40,156(126 \text { bp) G533C: } 40,105(G \rightarrow T) \\
\text { rs75873440: } 43,607,621\end{array}$ \\
\hline 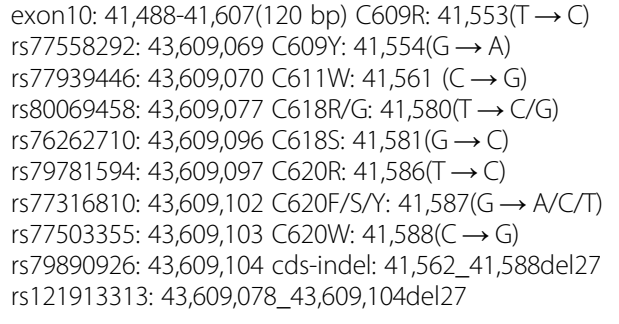 \\
\hline n12: 44,516-44,663 (148 bp) \\
\hline
\end{tabular}

exon13: 46, 305-46,412 (108 bp) S765P: 46,313(T $\rightarrow$ C) rs75075748: 43,613,829 E768E: 46,324(G $\rightarrow$ A/C) rs78014899: 43,613,840 V7781: 46,352(G $\rightarrow$ A) rs75686697: 43,613,868 L790F: 46,390(G $\rightarrow$ C) rs75030001: 43,613,906 Y791F: 46,392(A $\rightarrow$ T) rs77724903: 43,613,908

exon14: 47, 463-47,677 (215 bp) V804M: 47,480(G $\rightarrow$ A) T) rs79658334: $43,614,996$

exon15: 48,013-48,135 (123 bp) S891A: 48,076(T $\rightarrow$ G) rs75234356: 43,615,592 cds-indel: 48,051_48,053delAGCinsTTT rs 121913306 43,615,567_43,615,567delins R897Q: 48,095(G $\rightarrow$ A) rs76087194: 43,615,611 cds-indel: 48,097_48,108del12 rs121913309: 43,615,613_43,615,624del12

exon16: 49, 878-49,948 (71bp) M918T: 49,900( $\rightarrow$ C) rs74799832: 43,617,416 R912P: 49,882(G $\rightarrow$ C/T) rs78347871: 43,617,398

exon17: 51, 603-51,740 (138 bp)R972G: 51,715(A $\rightarrow$ G) rs76534745: 43,619,231

2q35

DIRC3 (noncoding RNA):218,148,746-218,621,316 (472571 bp)rs966423:218,310,340

$5 q 24$

Pre-miR-146a: 159,912,359-159,912,457(99bp) rs2910164: 159,912,418

$8 \mathrm{q} 24$

rs4733616: 128,662,095

$8 \mathrm{p} 12$

NRG1 transcript variant HRG-beta1c: $31,496,820-$ $32,622,558(1,125,738$ bp) rs2439302: 32,432,369

\section{Primers}

Localization \& product

5'-TGCTTGCTCTGATAGGAAAATG-3' 5'CCACAAAATGGATCCAGACA-3'

Chr7:140,453,250-140,453,078 (173 bp) intron: 176,315-176,371 exon15:176,372-176,487 (116 bp)

5'-CTITCCTCACAACCCCCTCC-3' 5'AGAGCGAGCACCTCATTTCC-3'

5'-CCTGTGCAGTCAGCAAGAGA-3' 5'CCTGTTCCCATGCCCTGATT-3'

5'-GGAAACCTGGATCCCACAGG-3' 5'GGGAGGGAAGTTTCATGGGG-3'

5'-GTGGGCCCAATGTGTGGATA -3' 5'-
CTCTTCAGGGTCCCATGCTG-3'

5'-CGGGGAATTTCTGTGGACGA-3' 5'ATGGCAGTGTCACACCAGAG-3'

5'-GAGGCAGAGAGCAAGTGGTT-3' 5'AATAGCACGAGTCGTCAGGC-3'

5'-TCTCACAGGGGATGCAGTATCTG3' 5'-GAGGCTGAGCGGAGTTCTAATTG-3'

5'-GCTCCAGCCCCTTCAAAGAT-3'5'CTITGAGCAGTTTGGGGCAC-3'

5'-CTCTGATGGGAGTGGCTTGG-3'5'CCACTCAGGCACCCCTTAAC-3'

5'-CGGCCTCGACCAACACTTAT-3' $5^{\prime}$-ACTGGGCGTCTCAACTACAATCTG $-3^{\prime}$ the intron region of DIRC3,

5'-ATTTACAGGGCTGGGACAG-3' 5'TCTTCCAAGCTCTTCAGCAG-3'

5'-CACCGGGGATTGGAAGAGATAAG-3' 5'- TGAAGCCACAGGGGAGAAAAGT -3'

5'-AATGCAAGAATGGCCTAACACAAT-3' 5'-AACCTGGGGSSSSSTCTGAAGC-3'
Chr10: 43,601,341-43,602, 077 (737 bp) intron: 33, 825-34,307\&34,504-34,561 exon5: 34,308-34,503 (196 bp) STS: 33,825-34,398

Chr10: 43,607,577-43,608,444 (868 bp) exon8: 40,061-40,155 (96 bp) intron: 40,156-40,784\&40,89640,928 exon9: 40,785-40,895 (111 bp)

Chr10: 43,608,459-43,609,249 (791 bp) intron: 40,943-41,487\&41,608-41,557 exon10: 41,488-41,607 (120 bp) STS: 41558-41733
Chr10: 43,611,512-43,612,272 (761 bp) intron: 43,996-44,515\&44,664-44,756 exon10: 44,516-44,663 (148 bp)

Chr10: 43,613,496-43,614,200 (705 bp) intron: 45,980-46,304\&46,413-46,684 exon13: 46, 30546,412 (108 bp) misc_difference: 46,327

Chr10: 43,614,767-43,615,517 (751 bp) intron: $47,251-47,462 \& 47,678-48,001$ exon $14: 47,463-$ 47,677 (215 bp)

Chr10: 43,615,159-43,615,837 (679 bp) exon14: ' 47,643-47,677 (35 bp) intron: 47,678-48,012\&48,13648,321 exon15: 48,013-48,135 (123 bp)

Chr10: 43,617,229-43,617,941 (713 bp) intron: 49,713-49, 877\&49, 949-50,425 exon16: 49,87849,948 (71 bp) STS: 49,832-50,007

Chr10: 43,618,871-43,619,601 (713 bp) intron: 51,355-51, 602\&51,741-52,085 exon17: 51, $603-$ $51,740(138 \mathrm{bp})$

Chr2: $218,310,115-218,310,537(423$ bp) located in

Chr5: 159,912,297-159,912,523(227 bp)

Chr8:128,661,750-128,662,159(410 bp)

Chr8: 32,432,326-32,432,660(334 bp) located in intron of NRG1 
Table 2 Sequences of the primers (Continued)

\begin{tabular}{|c|c|c|}
\hline \multicolumn{3}{|l|}{$9 q 22.33$} \\
\hline rs965513:100,556,109 & $\begin{array}{l}\text { 5'-CCGGCTTGAGTTCAGGTATGTAGT-3' } \\
\text { 5'-CCAGGCTCAGGTTATGTCTITGTT-3' }\end{array}$ & Chr9: 100,555,758-100,556,177(420bp) \\
\hline \multicolumn{3}{|l|}{$9 q 22$} \\
\hline $\begin{array}{l}\text { FoxE1: 100,615,537-100,618,997(3,460 bp)rs1867277: } \\
100,615,914\end{array}$ & $\begin{array}{l}\text { 5'-AGACCAGCTGCAGCCACCCCAACC-3' } \\
\text { 5'-GTCTCGCCGCGCTCTTCCTTCACG-3' }\end{array}$ & $\begin{array}{l}\text { Chr9: } 100,615,806-100,616,270(465 \text { bp)located in } \\
\text { the STS of FoxE1 }\end{array}$ \\
\hline \multicolumn{3}{|l|}{$14 q 13.3$} \\
\hline rs944289: $36,649,246$ & $\begin{array}{l}\text { 5'-CCAGTGGCCCCGCAGGTT-3'5'- } \\
\text { GAAAAGCACGTCTCCCCACAGTCC-3' }\end{array}$ & Chr14: 36,648,944-36,649,435(492bp) \\
\hline rs116909374: 36,738,361 & $\begin{array}{l}\text { 5'-TGTAATGGCAGCTCTTGACCTT-3' 5'- } \\
\text { ACCTITGATTGCCCTTAGTTGA-3' }\end{array}$ & Chr14: 36,738,229-36,738,674(446 bp) \\
\hline
\end{tabular}

and III3), 35 and 25 years old respectively, were diagnosed with MNG and PTC (Figure 1); As the family members resided in different cities and denied radiation exposure, no other neoplasia syndromes or somatic genetic alterations in the tumor DNA was observed, according to diagnostic criteria of familial MNG with PTC [6], we considered the Chinese family presented hereditary predisposition to PTC.

\section{The comparison of the susceptibility loci}

In the current study, we investigated the exon 15 of $B R A F$, since several SNPs in the genomic region were reported to contribute to PTC in a Chinese population [8] and the transversions in exon 15 are the common morphotype-specific mutation in adult sporadic PTC. The results were shown in Table 3: the examined BRAF sequences involved these susceptibility loci carried no risk alleles and were the same as common TT at $B R A F^{\mathrm{T} 1799 \mathrm{~A}}$ and $\mathrm{AA}$ at $B R A F^{\mathrm{A} 1801 \mathrm{G}}$. No any other genetic mutation was found in the family members.

We also investigated all the known RET susceptibility loci to family thyroid diseases in this Chinese family. Either, no known RET susceptibility loci was mutational in the family members. However, it needs to mention that in the genomic regions which we sequenced, the RET introns contained certain differences among the family members, such as introns between exon 4 and 5 (rs35800403 \& rs2742243), between 11 and 12 (rs2256550), between 14 and 15 (rs11238441 \& rs2472737) (Table 3), and also, there was a new $\mathrm{C}$ to $\mathrm{T}$ heterozygous allele in the upstream of rs111306965 in the genome of memberII8 andII10 by repeatedly sequencing. Additionally, rs1800863 in exon 15 contained variants of synonymous code substitution in the genome of several family members (II2, II5 \& II10).

With respect to the other susceptibility loci identified, as shown in Table 3, all the members from the Chinese family had equal sequences in the (1) DIRC3 susceptibility locus at 2q35, (2) Pre-miR-146a susceptibility locus at 5q24, (3) NRG1 transcript variant HRG-beta1c susceptibility locus at $8 \mathrm{p} 12$, (4) susceptibility loci of $8 \mathrm{q} 24$, and (5) susceptibility loci of 9q22. Noticeably, all the family members including the proband's father without thyroid disease were homozygous for the risk alleles of (1) rs966423 (CC) in DIRC3, (2) rs2910164 (CC) in Pre-miR-146a and (3) rs2439302 (GG) in HRG-beta1c; While all these members from the Chinese family contained no risk allele of (4) rs4733616 at 8q24, (5) rs965513 and rs1867277 at 9q22.

For the susceptibility loci of $14 \mathrm{q} 13.3$, as $14 \mathrm{q}$ was reported to be specifically linked with MNG1 and a form of MNG with PTC $[25,26]$, it is worth to mention that the risk $\mathrm{T}$ allele of rs944289 was presented in the sequences of the most family members affected with thyroid disease (II2 \& II8, MNG; II5 \& III2, MNG with PTC; Table 1). The sequence result in Table 3 showed that both MNG with PTC family members II5 and III2 were heterozygous (CT) and the 2 MNG family members II2 and II10 were homozygous (TT) at rs944289 locus (Table 3). While for another susceptibility locus of rs116909674 at 14q13.3 which we checked, none of the studied Chinese family members carried the risk alleles.

\section{Discussion}

The Chinese family presented hereditary predisposition to PTC, but currently the genetic incline to PTC is unknown. With the aim of understanding the involvement of genetic factors underlying $\mathrm{fPTC}$, we analyzed the reported possible PTC susceptibility genetic regions by sequence in the Chinese family members who consented to join the study. First, it is worthy to mention that no risk allele of rs965513 (A) or rs1867277 (A) at 9q22 was observed among the Chinese family members. These susceptibility loci of FOXE1 at $9 \mathrm{q} 22$ were related to radiation-induced PTC [19], hence it may be reasonable that the FOXE1 risk alleles were not presented in the familial form of MNG with PTC, as the members denied radiation exposure and resided in quite different environment. Either, the Chinese family members carried no risk allele of rs4733616 (T) at 8q24 which has been shown to be associated with sporadic PTC in Europeans [14-16], but the pathogenic role of the allele is currently unknown. 
Table 3 Sequences of susceptibility loci in the family members

\begin{tabular}{|c|c|c|c|c|c|c|c|c|c|c|c|}
\hline \multirow[t]{2}{*}{ Chromosome } & \multicolumn{2}{|l|}{ BRAF at Chr7q34 } & \multicolumn{9}{|c|}{ RET at Chr10q11.2: 43,572,517-43,625,799 } \\
\hline & rs121913364 & rs113488022 & rs35800403 & rs2742243 & rs77702891 & rs80236571 & rs75873440 & rs77558292 & rs77939446 & \multicolumn{2}{|l|}{ rs80069458 } \\
\hline Locus & $\begin{array}{l}140,453,134 \\
\text { exon15 }\end{array}$ & $\begin{array}{l}140,453,136 \\
\text { exon15 }\end{array}$ & $\begin{array}{l}43,601,415 \\
\text { intron }\end{array}$ & $43,601,749$ intron & $\begin{array}{l}43,601,894 \\
\text { exon5 }\end{array}$ & $\begin{array}{l}43,601,945 \\
\text { exon5 }\end{array}$ & $\begin{array}{l}43,607,621 \\
\text { exon8 } \& 9\end{array}$ & $\begin{array}{l}43,609,069 \\
\text { exon10 }\end{array}$ & $\begin{array}{l}43,609,070 \\
\text { exon10 }\end{array}$ & \multicolumn{2}{|c|}{$43,609,077$ exon 10} \\
\hline Allele & $\begin{array}{l}\text { A:germline G: } \\
\text { germline somatic } \\
\mathrm{A} \rightarrow \mathrm{G} \text { missense }\end{array}$ & $\begin{array}{l}\text { A:germline; } \\
\text { somatic C:somatic } \\
\text { T:germline } T \rightarrow A \\
\text { missense }\end{array}$ & $\mathrm{G} / \mathrm{C}$ & $\mathrm{T} / \mathrm{C}$ & $\begin{array}{l}\text { A:germline } \\
\text { G:germline } \\
G \rightarrow A \\
\text { missense }\end{array}$ & $\begin{array}{l}\text { A:germline } \\
\text { G:germline } \\
\mathrm{G} \rightarrow \mathrm{A} \\
\text { missense }\end{array}$ & $\begin{array}{l}\text { G:germline } \\
\text { T:germline } \\
G \rightarrow T \\
\text { missense }\end{array}$ & $\begin{array}{l}T: \text { germline } \\
C: \text { germline } \\
T \rightarrow C \\
\text { missense }\end{array}$ & $\begin{array}{l}\text { G:germline A: } \\
\text { germline } \mathrm{G} \rightarrow \mathrm{A} \\
\text { missense }\end{array}$ & \multicolumn{2}{|l|}{$\begin{array}{l}\text { C:germline } \\
\text { G:germline } \\
\mathrm{C} \rightarrow \mathrm{G} \\
\text { missense }\end{array}$} \\
\hline II1 normal & $\pi$ & AA & GC & TC & GG & GG & GG & $\pi$ & GG & \multicolumn{2}{|l|}{ CC } \\
\hline $112 \mathrm{MNG}$ & $\pi$ & $\mathrm{AA}$ & GG & $\pi$ & GG & GG & GG & $\pi$ & GG & \multicolumn{2}{|l|}{ CC } \\
\hline III2 PTC & $\pi$ & AA & GC & $\mathrm{TC}$ & GG & GG & GG & $\pi$ & GG & \multicolumn{2}{|l|}{ CC } \\
\hline II5 PTC & $\pi$ & AA & GG & $\pi$ & GG & GG & GG & $\pi$ & GG & \multicolumn{2}{|l|}{ CC } \\
\hline $118 \mathrm{MNG}$ & $\pi$ & $\mathrm{AA}$ & GC & $\mathrm{TC}$ & GG & GG & GG & $\pi$ & GG & \multicolumn{2}{|l|}{ CC } \\
\hline$\| 10 \mathrm{MNG}$ & $\pi$ & $\mathrm{AA}$ & GG & $\pi$ & GG & GG & GG & $\pi$ & GG & \multicolumn{2}{|l|}{ CC } \\
\hline \multirow[t]{2}{*}{ Chromosome } & \multicolumn{11}{|c|}{ RET at Chr10q11.2: 43,572,517-43,625,799 } \\
\hline & rs76262710 & rs79781594 & rs77316810 & rs77503355 & rs79890926 & rs121913313 & rs 2256550 & rs75075748 & rs78014899 & rs75686697 & rs75030001 \\
\hline Locus & $\begin{array}{l}43,609,096 \\
\text { exon10 }\end{array}$ & $\begin{array}{l}43,609,097 \\
\text { exon10 }\end{array}$ & $\begin{array}{l}43,609,102 \\
\text { exon10 }\end{array}$ & $43,609,103$ exon 10 & $\begin{array}{l}43,609,104 \\
\text { exon10 }\end{array}$ & $\begin{array}{l}43,609,104 \\
\text { exon10 }\end{array}$ & $\begin{array}{l}43,611,865 \\
\text { exon12 }\end{array}$ & $\begin{array}{l}43,613,829 \\
\text { exon13 }\end{array}$ & $\begin{array}{l}43,613,840 \\
\text { exon13 }\end{array}$ & $\begin{array}{l}43,613,868 \\
\text { exon13 }\end{array}$ & $\begin{array}{l}43,613,906 \\
\text { exon13 }\end{array}$ \\
\hline Allele & $\begin{array}{l}\text { C:germline G: } \\
\text { germline } \mathrm{T}: \\
\text { germline } \mathrm{T} \rightarrow \\
\text { C\&T } \rightarrow \mathrm{G} \\
\text { missense }\end{array}$ & $\begin{array}{l}\text { C:germline G: } \\
\text { germline } \mathrm{G} \rightarrow C \\
\text { missense }\end{array}$ & $\begin{array}{l}\text { C:germline } \\
\mathrm{T}: \text { germline } \\
\mathrm{T} \rightarrow \mathrm{C} \\
\text { missense }\end{array}$ & $\begin{array}{l}\text { A:germline C:germline } \\
\text { G:germline T:germline } \\
G \rightarrow A \& G \rightarrow C \& G \rightarrow T \\
\text { missense }\end{array}$ & $\begin{array}{l}\text { C:germline } \\
\text { G:germline } \\
C \rightarrow G \\
\text { missense }\end{array}$ & $\begin{array}{l}\text { not } \\
\text { availiable } \\
\text { cds-indel }\end{array}$ & $\mathrm{T} / \mathrm{C}$ intron & $\begin{array}{l}\text { C:germline } \\
T: \text { germline } \\
T \rightarrow C \\
\text { missense }\end{array}$ & $\begin{array}{l}\text { A:unkown } C: \\
\text { somatic } G: \\
\text { germline } G \rightarrow A \& \\
G \rightarrow C \text { cds-synon }\end{array}$ & $\begin{array}{l}\text { A:germline } \\
\text { G:germline } \\
G \rightarrow A \\
\text { missense }\end{array}$ & $\begin{array}{l}\text { C:unkown } \\
\text { G:germline } \\
\mathrm{G} \rightarrow \mathrm{C} \\
\text { missense }\end{array}$ \\
\hline II1 normal & $\pi$ & GG & $\pi$ & GG & $\mathrm{CC}$ & no del & TC & $\pi$ & GG & GG & GG \\
\hline $112 \mathrm{MNG}$ & $\pi$ & GG & $\pi$ & GG & CC & no del & $\pi$ & $\pi$ & GG & GG & GG \\
\hline III2 PTC & $\pi$ & GG & $\pi$ & GG & $\mathrm{CC}$ & no del & $\mathrm{TC}$ & $\pi$ & GG & GG & GG \\
\hline ॥5 PTC & $\pi$ & GG & $\pi$ & GG & $\mathrm{CC}$ & no del & $\pi$ & $\pi$ & GG & GG & GG \\
\hline $118 \mathrm{MNG}$ & $\pi$ & GG & $\pi$ & GG & $\mathrm{CC}$ & no del & TC & $\pi$ & GG & GG & GG \\
\hline ॥10 MNG & $\pi$ & GG & $\pi$ & GG & CC & no del & $\pi$ & $\pi$ & GG & GG & GG \\
\hline \multirow[t]{2}{*}{ Chromosome } & \multicolumn{11}{|c|}{ RET at Chr10q11.2: $43,572,517-43,625,799$} \\
\hline & rs77724903 & rs79658334 & rs11238441 & new & rs2472737 & rs121913306 & rs75234356 & rs76087194 & rs121913309 & rs1800863 & rs78347871 \\
\hline Locus & $\begin{array}{l}43,613,908 \\
\text { exon13 }\end{array}$ & $\begin{array}{l}43,614,996 \\
\text { exon14 }\end{array}$ & $\begin{array}{l}43,615,382 \\
\text { intron }\end{array}$ & $43,615,404$ intron & $\begin{array}{l}43,615,505 \\
\text { intron }\end{array}$ & $\begin{array}{l}43,615,567 \\
\text { exon15 }\end{array}$ & $\begin{array}{l}43,615,592 \\
\text { exon15 }\end{array}$ & $\begin{array}{l}43,615,611 \\
\text { exon } 15\end{array}$ & $\begin{array}{l}43,615,613 \\
\text { exon15 }\end{array}$ & $\begin{array}{l}43,615,633 \\
\text { exon15 }\end{array}$ & $\begin{array}{l}43,617,398 \\
\text { exon16 }\end{array}$ \\
\hline Allele & $\begin{array}{l}\text { A:germline } \mathrm{T} \text { : } \\
\text { germline } \mathrm{A} \rightarrow \mathrm{T} \\
\text { missense }\end{array}$ & $\begin{array}{l}\text { A:unkown } G \text { : } \\
\text { germline } T: \\
\text { germline } G \rightarrow A \\
\& G \rightarrow T \text { missense }\end{array}$ & $\mathrm{C} / \mathrm{T}$ & $\mathrm{C} / \mathrm{T}$ & $\mathrm{G} / \mathrm{A}$ & $\begin{array}{l}\text { AGC: } \\
\text { germline } \\
\text { TIT:somatic } \\
\text { cds-indel }\end{array}$ & $\begin{array}{l}\text { G:germline } \\
\mathrm{T}: \text { germline } \\
\mathrm{T} \rightarrow \mathrm{G} \\
\text { missense }\end{array}$ & $\begin{array}{l}\text { A:germline } \\
\mathrm{G}: \text { germline } \\
\mathrm{G} \rightarrow \mathrm{A} \\
\text { missense }\end{array}$ & $\begin{array}{l}\text { not availiable cds- } \\
\text { indel }\end{array}$ & $\begin{array}{l}\text { not } \\
\text { availiable C/ } \\
\text { G cds-synon }\end{array}$ & $\begin{array}{l}\text { C:germline } \\
\text { G:germline } \\
\mathrm{G} \rightarrow \mathrm{C} \\
\text { missense }\end{array}$ \\
\hline
\end{tabular}


Table 3 Sequences of susceptibility loci in the family members (Continued)

\begin{tabular}{|c|c|c|c|c|c|c|c|c|c|c|c|}
\hline II1 normal & $\mathrm{AA}$ & GG & CC & CC & $\mathrm{GA}$ & AGC & $\pi$ & GG & no del & CC & GG \\
\hline $112 \mathrm{MNG}$ & $\mathrm{AA}$ & GG & $\mathrm{CT}$ & CC & GG & AGC & $\pi$ & GG & no del & CG & GG \\
\hline III2 PTC & $\mathrm{AA}$ & GG & CC & CC & GA & AGC & $\pi$ & GG & no del & CC & GG \\
\hline II5 PTC & $\mathrm{AA}$ & GG & $\mathrm{CT}$ & CC & GG & AGC & $\pi$ & GG & no del & CG & GG \\
\hline ॥8 MNG & $\mathrm{AA}$ & GG & CC & CT & GA & AGC & $\pi$ & GG & no del & CC & GG \\
\hline$\| 10 \mathrm{MNG}$ & AA & GG & $\mathrm{CT}$ & CT & GG & AGC & $\pi$ & GG & no del & CG & GG \\
\hline
\end{tabular}

The SNP alleles are shown as the reference/variant, referring to NCBI Build 36.3; the common to mutant is showed by " $\rightarrow$ "; the risk allele is indicated with an asterisk and outlined if presented in the family members, and the different sequences among the family members are shadowed. 
Our results verified that, for the predisposition to familial form of PTC and radiation-related PTC, their mechanism of PTC susceptibility did not completely overlap each other, since the genetic determinants associated with radiation-related PTC were not presented in the Chinese family members with PTC and MNG.

It is also noticeable that all the family members were homozygous for the risk alleles of rs966423 (CC) at 2q35, rs2910164 (CC) at 5q24 and rs2439302 (GG) at 8p12. All these susceptibility loci have been reported to associate with sporadic PTC $[11,13]$, but currently the pathogenic functions of these alleles are not known well. We think all these risk alleles might contribute jointly to the development of MNG and PTC in the Chinese family members; while considering the risk alleles also presented in the proband's father with normal thyroid, it is possible that different pathogenic mechanisms exist to activate the tumor transformation in the family members with thyroid disease.

Interestingly, we observed that the frequency of $\mathrm{T}$ risk allele of rs944289 at 14q13.3 locus was increased in these MNG and PTC Chinese family members (C: $\mathrm{T}=0.4: 0.6 \mathrm{vs}$ 0.571:0.429 in normal people). Several studies suggested the possible genetic predisposition of 14q to familial PTC [25] while no association between the radiation-related PTC and 14q13.3 [19]. Also, family nontoxic MNG locus maps to chromosome 14q [24]. Further research suggested that rs944289 was located in a CEBP-alpha/CEBP-beta binding element in the 5-prime UTR of a thyroid-specific lincRNA gene, papillary thyroid carcinoma susceptibility candidate 3 (PTCSC3), PTCSC 3 had the characteristics of a tumor suppressor, the rs944289 $\mathrm{T}$ risk allele reduced PTCSC3 promoter activation and thereby predisposes to PTC [21]. Nevertheless, the tumor suppression mechanism of PTCSC3 is currently unknown. In addition, the thyroid transcription factor of NK2 homeobox 1, NKX2-1, is also located in the 14q13.3; NKX2-1 regulates the expression of thyroid-specific genes involved in morphogenesis. But how rs944289 was associated with NKX2-1 remains to be investigated. Also, we investigated PTC susceptibility locus of rs116909374 (T) locating between PTCSC3 and NKX2-1 at the same 14q, the family members carried no risk allele at all. Hence, our current work implied the possible role of rs944289 in familial MNG with PTC. Whereas, it is surprise that heterozygosity as CT rather than homozygosity as TT presented in the APTC family members; the same phenomenon was once suggested as a possible special form of genetic epistasis in the rs2910164 allele of pre-miR-146a gene [12], which may also contributed to this Chinese fMNG with PTC as shown by the study. Briefly, our results in the Chinese family agreed that rs944289 but not rs116909374 at 14q13.3 locus might be associated with genetic predisposition to familial form of MNG with PTC; it will be intriguing to further analyze the pathogenic link between rs944289 and the disease.
As we failed to detect somatic genetic alterations in the tumor DNA, such as the BRAF and RET protooncogene in the Chinese family members, in the current study, we investigated the genomic region containing the $B R A F$ susceptible variants in sporadic PTC, and also all the known $R E T$ susceptibility loci to thyroid diseases (Tables 2 and 3). Our sequencing results confirmed that the BRAF and RET mutations were not germline mutations or susceptibility genetic events in this Chinese family. However, we noticed that in the sequenced RET genetic region, several different heterozygous alleles were presented among the Chinese family members, and most alleles were in the intron region. Recently, the chromosomal fragile sites breakage was proposed to cause PTC by forming chromosome rearrangement [26]. The chromosomal fragile sites are regions of the genome with a high susceptibility to forming DNA breaks and are often associated with cancer. Exposure to a variety of external factors such as chemotherapeutic, dietary and environmental compounds can induce and accelerate the fragile site breakage. Several intron regions of $R E T$ were identified as DNA breakage region. Hence, we are wondering if it is possible that the polymorphisms of introns could link to the structural difference in the RET region and could impact the related chromosome architecture and thyroid gene expression, albeit there was no $R E T$ mutation in the cancerous thyroid. Interestingly, there were 2 related facts to be considered: (1) it was shown that transfecting thyroid cells with RET produced morphological changes in nuclei that mimicked those seen in PTC [27]; (2) it is curious that the RET gene is not expressed in the thyroid follicular cells from which PTC develops, but rearrangements of the RET are found in PTC cases [28]. Hence, we think it will be intriguing to investigate the association between the genomic structural of RET region and the regulation mechanism of RET.

Our work may provide additional evidence to the genetic predisposition to familial form of MNG with PTC. Due to unavailability of samples and the complex of pathogenesis, the current studied Chinese family was small and limited. Nonetheless, for complex diseases like PTC, there may be many genes influencing risk as well as the effects of environment, also, it is much more difficult to collect pedigrees with multiple affected relatives and there is no guarantee of the same (or any) gene (SNP) segregating in these family. To provide insights into the genetic risk factors for familiar PTC, more researches are needed.

\section{Conclusions}

Based on our current investigation in the Chinese fMNG with PTC, the risk allele homozygote of rs966423 (CC) at $2 \mathrm{q} 35, \mathrm{rs} 2910164$ (CC) at 5q24 and rs2439302 (GG) at 
8p12 could contribute to the fMNG with PTC, while the other identified risk alleles for sporadic PTC or radiation-related PTC might not be involved. Also, corresponding to the previous studies on the association between chromosome 14q and fMNG with PTC, our work approved that rs944289 but not rs116909374 at 14q13 locus might be associated with genetic predisposition to a Chinese family MNG with PTC. Though several different heterozygous alleles in the RET introns presented, the common BRAF and RET mutations were not susceptibility genetic events in this Chinese family.

\section{Competing interests}

The authors have non-financial competing interests.

\section{Authors' contributions}

SY L, YQ L and WZ S designed the molecular genetic studies, participated in the sequence alignment and drafted the manuscript. DD D and $G X$ carried out the immunohistochemical assay. SP D and YM L have been involved in revising the manuscript critically. ZL T, JY H participated in data acquisition and helped to draft the manuscript. All authors read and approved the final manuscript.

\section{Acknowledgments}

We thank the members of the Chinese fMNG with PTC family for their essential contribution to scientific research. We thank Dr. Hongji Yang and the colleagues in Department of General Surgery, Sichuan Academy of Medical Science, Sichuan Provincial People's Hospital, for their support and collaboration.

\section{Funding}

This study was supported by the research grants (to Wenzhong Song and to Shunyao Liao) from Sichuan Provincial Health Department, China (100450,120074)

\section{Author details}

'Diabetes \& Endocrinology Center, Sichuan Academy of Medical Science, Sichuan Provincial People's Hospital, Chengdu 610072, China. ${ }^{2}$ Department of Thyroid Disease \& Nuclear Medicine, Sichuan Academy of Medical Science, Sichuan Provincial People's Hospital, Chengdu 610072, China. ${ }^{3}$ Department of Medical Genetics and Division of Morbid Genomics, State Key Laboratory of Biotherapy, West China Hospital, Sichuan University, Chengdu 610041, China. ${ }^{4}$ Department of Surgery, Harvard Medical School, Massachusetts General Hospital, Boston, MA, USA. ${ }^{5}$ Department of Pathology, Sichuan Academy of Medical Science, Sichuan Provincial People's Hospital, Chengdu 610072, China

Received: 4 June 2013 Accepted: 17 October 2013

Published: 21 October 2013

\section{References}

1. Nosé V: Familial thyroid cancer: a review. Mod Pathol 2011, 24(Suppl 2):S19-S33.

2. Khan A, Smellie J, Nutting C, Harrington K, Newbold K: Familial nonmedullary thyroid cancer: a review of the genetics. Thyroid 2010, 20(7):795-801. Review.

3. Bonora E, Tallini G, Romeo G: Genetic predisposition to familial nonmedullary thyroid cancer: an update of molecular findings and state-of-the-Art studies. J Oncol 2010, 2010. 385206.

4. Hemminki K, Eng C, Chen B: Familial risks for nonmedullary thyroid cancer. J Clin Endocrinol Metab 2005, 90(10):5747-5753.

5. Morrison PJ, Atkinson AB: Genetic aspects of familial thyroid cancer. Oncologist 2009, 14(6):571-577.

6. Musholt TJ, Musholt PB, Petrich T, Oetting G, Knapp WH, Klempnauer J: Familial papillary thyroid carcinoma: genetics, criteria for diagnosis, clinical features, and surgical treatment. World J Surg 2000, 24(11):1409-1417.

7. Nikiforov YE, Nikiforova MN: Molecular genetics and diagnosis of thyroid cancer. Nat Rev Endocrinol 2011, 7(10):569-580.
8. Shifrin AL, Ogilvie JB, Stang MT, Fay AM, Kuo YH, Matulewicz T, Xenachis CZ, Vernick JJ: Single nucleotide polymorphisms act as modifiers and correlate with the development of medullary and simultaneous medullary/papillary thyroid carcinomas in 2 large, non-related families with the RET V804M proto-oncogene mutation. Surgery 2010, 148(6):1274-1280.

9. Shifrin AL, Fay A, Kuo YH, Ogilvie J: Response to "Single nucleotide polymorphisms and development of hereditary medullary thyroid cancer in V804M RET families: disease modification or linkage disequilibrium? ". Surgery 2012, 151(6):902-903.

10. Zhang Q, Song F, Zheng H, Zhu X, Song F, Yao X, Zhang L, Chen K: Association between single-nucleotide polymorphisms of BRAF and papillary thyroid carcinoma in a Chinese population. Thyroid 2013, 23(1):38-44.

11. Gudmundsson J, Sulem P, Gudbjartsson DF, Jonasson JG, Masson G, He H, Jonasdottir A, et al: Discovery of common variants associated with low TSH levels and thyroid cancer risk. Nat Genet 2012, 44(3):319-322.

12. Jazdzewski K, Murray EL, Franssila K, Jarzab B, Schoenberg DR, de la Chapelle A: Common SNP in pre-miR-146a decreases mature miR expression and predisposes to papillary thyroid carcinoma. Proc Natl Acad Sci USA 2008, 105(20):7269-7274

13. Jazdzewski K, Liyanarachchi S, Swierniak M, Pachucki J, Ringel MD, Jarzab B, de la Chapelle A: Polymorphic mature microRNAs from passenger strand of pre-miR-146a contribute to thyroid cancer. Proc Natl Acad Sci USA 2009, 106(5):1502-1505.

14. Neta G, Yu CL, Brenner A, Gu F, Hutchinson A, Pfeiffer R, Sturgis EM, Xu L, Linet MS, Alexander BH, Chanock S, Sigurdson AJ: Common genetic variants in the $8 q 24$ region and risk of papillary thyroid cancer. Laryngoscope 2012, 122(5):1040-1042.

15. He H, Nagy R, Liyanarachchi S, Jiao H, Li W, Suster S, Kere J, de la Chapelle A: A susceptibility locus for papillary thyroid carcinoma on chromosome 8q24. Cancer Res 2009, 69(2):625-631.

16. Jones AM, Howarth KM, Martin L, Gorman M, Mihai R, Moss L, Auton A, Lemon C, Mehanna H, Mohan H, Clarke SE, Wadsley J, Macias E, Coatesworth A, Beasley M, Roques T, Martin C, Ryan P, Gerrard G, Power D, Bremmer C, Consortium TCUKIN, Tomlinson I, Carvajal-Carmona LG: Thyroid cancer susceptibility polymorphisms: confirmation of loci on chromosomes $9 q 22$ and $14 q 13$, validation of a recessive $8 q 24$ locus and failure to replicate a locus on 5q24. J Med Genet 2012, 49(3):158-163.

17. Gudmundsson J, Sulem P, Gudbjartsson DF, Jonasson JG, Sigurdsson A, Bergthorsson JT, et al: Common variants on $9 q 22.33$ and $14 q 13.3$ predispose to thyroid cancer in European populations. Nat Genet 2009, 41(4):460-464.

18. Matsuse M, Takahashi M, Mitsutake N, Nishihara E, Hirokawa M, Kawaguchi T, Rogounovitch T, Saenko V, Bychkov A, Suzuki K, Matsuo K, Tajima K, Miyauchi A, Yamada R, Matsuda F, Yamashita S: The FOXE1 and NKX2-1 loci are associated with susceptibility to papillary thyroid carcinoma in the Japanese population. J Med Genet 2011, 48(9):645-648.

19. Takahashi M, Saenko VA, Rogounovitch TI, Kawaguchi T, Drozd VM, Takigawa-Imamura H, Akulevich NM, Ratanajaraya C, Mitsutake N, Takamura N, Danilova LI, Lushchik ML, Demidchik YE, Heath S, Yamada R, Lathrop M, Matsuda F, Yamashita S: The FOXE1 locus is a major genetic determinant for radiation-related thyroid carcinoma in Chernobyl. Hum Mol Genet 2010, 19(12):2516-2523.

20. Landa I, Ruiz-Llorente S, Montero-Conde C, Inglada-Pérez L, Schiavi F, Leskelä $S$, et al: The variant rs1867277 in FOXE1 gene confers thyroid cancer susceptibility through the recruitment of USF1/USF2 transcription factors. PLoS Genet 2009, 5(9):e1000637.

21. Jendrzejewski J, He H, Radomska HS, Li W, Tomsic J, Liyanarachchi S, Davuluri RV, Nagy R, de la Chapelle A: The polymorphism rs944289 predisposes to papillary thyroid carcinoma through a large intergenic noncoding RNA gene of tumor suppressor type. Proc Natl Acad Sci USA 2012, 109(22):8646-8651.

22. Malchoff CD, Sarfarazi M, Tendler B, Forouhar F, Whalen G, Joshi V, Arnold A, Malchoff DM: Papillary thyroid carcinoma associated with papillary renal neoplasia: genetic linkage analysis of a distinct heritable tumor syndrome. J Clin Endocrinol Metab 2000, 85(5):1758-1764.

23. McKay JD, Lesueur F, Jonard L, Pastore A, Williamson J, Hoffman L, et al: Localization of a susceptibility gene for familial nonmedullary thyroid carcinoma to chromosome 2q21. Am J Hum Genet 2001, 69(2):440-446.

24. Cantara S, Pisu M, Frau DV, Caria P, Dettori T, Capezzone M, Capuano S, Vanni R, Pacini F: Telomere abnormalities and chromosome fragility in patients affected by familial papillary thyroid cancer. J Clin Endocrinol Metab 2012, 97(7):E1327-E1331. 
25. Bignell GR, Canzian F, Shayeghi M, Stark M, Shugart YY, Biggs P, et al: Familial nontoxic multinodular thyroid goiter locus maps to chromosome $14 q$ but does not account for familial nonmedullary thyroid cancer. Am J Hum Genet 1997, 61(5):1123-1130.

26. Bakhsh A, Kirov G, Gregory JW, Williams ED, Ludgate M: A new form of familial multi-nodular goiter with progression to differentiated thyroid cancer. Endocr Relat Cancer 2006, 13(2):475-483.

27. Fischer AH, Bond J, Taysavang P, Battles OE, Wynford-Thomas D: Papillary thyroid carcinoma oncogene (RET/PTC) alters the nuclear envelope and chromatin structure. Am J Pathol 1998, 153(5):1443-1450.

28. Kitamura Y, Minobe K, Nakata T, Shimizu K, Tanaka S, Fujimori M, Yokoyama S, Ito $K$, Onda M, Emi M: Ret/PTC3 is the most frequent form of gene rearrangement in papillary thyroid carcinomas in Japan. J Hum Genet 1999, 44(2):96-102.

doi:10.1186/1472-6823-13-48

Cite this article as: Liao et al:: Familial multinodular goiter syndrome with papillary thyroid carcinomas: mutational analysis of the associated genes in 5 cases from 1 Chinese family. BMC Endocrine Disorders 2013 13:48.

\section{Submit your next manuscript to BioMed Central and take full advantage of:}

- Convenient online submission

- Thorough peer review

- No space constraints or color figure charges

- Immediate publication on acceptance

- Inclusion in PubMed, CAS, Scopus and Google Scholar

- Research which is freely available for redistribution 